\title{
Associations between fruit, vegetable and legume intakes and prostate cancer risk: results from the prospective Supplémentation en Vitamines et Minéraux Antioxydants (SU.VI.MAX) cohort
}

\author{
Abou Diallo ${ }^{1,2 *}$, Mélanie Deschasaux ${ }^{1}$, Pilar Galan ${ }^{1}$, Serge Hercberg ${ }^{1,2}$, Laurent Zelek ${ }^{1,3}$, \\ Paule Latino-Martel ${ }^{1}$ and Mathilde Touvier ${ }^{1}$ \\ ${ }^{1}$ Sorbonne Paris Cité Epidemiology and Biostatistics Research Center, Inserm U1153, Inra U1125, Cnam, Paris 13, 5 and 7 \\ Universities, Nutritional Epidemiology Research Team (EREN), 13 avenue de Paris, 93000 Bobigny, France \\ ${ }^{2}$ Public Health Department, Avicenne Hospital, 125 rue de Stalingrad, 93000 Bobigny, France \\ ${ }^{3}$ Oncology Department, Avicenne Hospital, 125 rue de Stalingrad, 93000 Bobigny, France \\ (Submitted 30 June 2015 - Final revision received 15 December 2015 - Accepted 19 January 2016 - First published online 7 March 2016)
}

\section{Abstract}

Although experimental studies suggest that fruits, vegetables and legumes may exert protective effects against prostate carcinogenesis through various bioactive compounds such as dietary fibre and antioxidants, epidemiological evidence is lacking. Notably, very few prospective studies have investigated the relationship between legume intake and prostate cancer risk. Our objective was to prospectively investigate the association between fruit, vegetable, tomato products, potatoes and legume intakes and prostate cancer risk. This study included 3313 male participants to the SUpplémentation en VItamines et Minéraux AntioXydants cohort (follow-up: 1994-2007) who completed at least three 24-h dietary records during the first 2 years of follow-up. Associations between tertiles of intake and prostate cancer risk were assessed by multivariate Cox proportional hazards models. After a median follow-up of 12.6 years, 139 incident prostate cancers were diagnosed. An inverse association was observed between prostate cancer risk and tertiles of legume intake (hazard ratio $(\mathrm{HR})_{\mathrm{T} 3} v \cdot \mathrm{T} 1=0.53 ; 95 \% \mathrm{CI} 0.34,0.85$; $\left.P_{\text {trend }}=0 \cdot 009\right)$. This association was maintained after excluding soya and soya products from the legume group $\left(\mathrm{HR} \mathrm{T}_{\mathrm{T} 3} v \cdot \mathrm{T} 1=0 \cdot 56 ; 95 \% \mathrm{CI} 0 \cdot 35\right.$, 0.89; $\left.P_{\text {trend }}=0.02\right)$. No association was observed between prostate cancer risk and tertiles of intakes of fruits $\left(P_{\text {trend }}=0 \cdot 25\right)$, vegetables $\left(P_{\text {trend }}=0.91\right)$, potatoes $\left(P_{\text {trend }}=0.77\right)$ and tomato products $\left(P_{\text {trend }}=0.09\right)$. This prospective study confirms the null association between fruit and non-starchy vegetable intakes and prostate cancer risk observed in most previous cohorts. In contrast, although very few prospective studies have been published on the topic, our results suggest an inverse association between legume intake and prostate cancer risk, supported by mechanistic plausibility. These results should be confirmed by large-scale observational and intervention studies.

Key words: Legumes: Fruits: Vegetables: Prospective studies: Prostate cancer

Prostate cancer is the most common cancer among males in France, representing $>28 \%$ of new cancer cases $^{(1)}$. It is the second most common cancer worldwide, and the fifth most common cause of cancer death among men: around $1 \cdot 1$ million new cases were recorded worldwide in 2012, accounting for $15 \%$ of all new cases of cancer in men ${ }^{(2)}$. Prostate cancer is a multifactorial pathology involving lifestyle, anthropometrics, genetics and environmental factors. Among all these determinants, nutrition represents a modifiable factor, and thus a potentially key lever for prevention ${ }^{(2,3)}$.

Fruits, vegetables and legumes represent broadly consumed food sources of bioactive compounds for which anti-carcinogenic roles have been suggested by experimental studies, either directly or after being metabolised by gut microbiota. Indeed, they contain vitamins and minerals, but also dietary fibre and polyphenols, for which anti-inflammatory, anti-insulin resistance and antioxidant properties have been demonstrated in animal or cell models, as well as a decreasing effect on circulating oestrogen and androgen levels (for dietary fibres), which could be beneficial against prostate carcinogenesis ${ }^{(4-8)}$.

However, epidemiological evidence is lacking regarding a potentially protective effect of fruit, vegetable and legume intakes on prostate cancer risk. In 2014, the World Cancer Research Fund (WCRF) and the American Institute for Cancer Research (AICR) performed a systematic review and meta-analyses of available studies and attributed the level of proof 'limited-no conclusion' to the associations between fruit, non-starchy vegetable, and legume intakes and prostate

Abbreviations: HR, hazard ratio; PSA, prostate-specific antigen; SU.VI.MAX, SUpplémentation en VItamines et Minéraux AntioXydants.

* Corresponding author: Dr A. Diallo, fax +3314838 8931, email a.diallo@eren.smbh.univ-paris13.fr 
cancer risk ${ }^{(9)}$. Although a substantial number of prospective studies was available regarding fruits and vegetables, it was not the case for legumes. Among the three available prospective studies on legume intake ${ }^{(10-12)}$, two showed inverse associations with prostate cancer risk $^{(10,11)}$. In addition, in a previous prospective investigation on the SUpplémentation en VItamines et Minéraux AntioXydants (SU.VI.MAX) cohort, we observed that dietary fibre intake from legumes was inversely associated with prostate cancer risk ${ }^{(13)}$

Our objective was to prospectively investigate the associations between fruit, vegetable, tomato products, potatoes and legume intakes and prostate cancer risk in the SU.VI.MAX cohort. Our hypothesis was that one or several of these food groups are inversely associated with prostate cancer risk.

\section{Methods}

\section{Participants}

The SU.VI.MAX study was at first designed as a randomised, double-blind, placebo-controlled primary prevention trial (registered at clinicaltrials.gov as NCT00272428) aiming to assess the effect of a daily supplementation with nutritional doses of antioxidants on the incidence of CVD and cancers ${ }^{(14)}$. In 1994-1995, 13017 individuals (7876 women and 5141 men) were enrolled for an 8-year intervention study. Follow-up of health events lasted until September 2007. The SU.VI.MAX study was conducted according to the Declaration of Helsinki guidelines and was approved by the Paris-Cochin Hospital Ethics Committee for Studies with Human Subjects (CCPPRB nos 706 and 2364, respectively) and the French National Commission for Computed Data and Individual Freedom (CNIL nos 334641 and 907094, respectively). Written informed consent was obtained from all the participants.

\section{Baseline data collection}

Dietary data. Every 2 months during the trial phase (1994-2002), participants were invited to complete a 24-h dietary record via the Minitel Telematic Network, a French telephone-based terminal equivalent to an Internet prototype used widely at the beginning of the study. These records were randomly distributed between weeks and weekends and over seasons to take into account intra-individual variability. Participants assessed portion sizes using a validated picture booklet ${ }^{(15)}$, and the amounts consumed from composite dishes were estimated using French recipes validated by food and nutrition professionals. The mean daily energy, alcohol, macronutrient and micronutrient intakes were estimated using a published French Food Composition Table ${ }^{(16)}$. During the trial phase, participants were advised against taking any self-prescribed supplementation.

Other covariates. Information regarding socio-demographics, smoking status, physical activity and family history of prostate cancer was collected by self-administered questionnaires from all participants at enrolment. Anthropometric measures (height and weight) were obtained during a medical examination by the study nurses and physicians.
A 35-ml fasting venous blood sample was collected into vacutainer tubes at baseline. Plasma samples were used to determine the concentrations of Se by flame atomic absorption spectrometry, $\alpha$-tocopherol by HPLC and total prostate-specific antigen (PSA) by immunoassay (Roche Diagnostics) ${ }^{(17,18)}$. PSA tests were performed only once, on baseline samples that were analysed later, at the end of the trial phase in 2002-2003, as part of a post hoc research protocol. Following these PSA tests (in 2002-2003), participants and their treating physicians were contacted by the SU.VI.MAX investigators if they had a PSA $\geq 4.0 \mu \mathrm{g} / \mathrm{l}$. Medical examinations following this PSA test were left to the discretion of the treating physician. There was no PSA follow-up during the study.

\section{Case ascertainment}

During the follow-up period, participants were invited to self-report health events (through a monthly questionnaire). All cases were verified with biopsies by histopathological examination in the hospital where they were diagnosed. An expert committee of physicians from the SU.VI.MAX study collected the corresponding pathological reports and validated all cancer cases $^{(14)}$. Cases were classified using the International Chronic Diseases Classification, 10th revision, Clinical Modification ${ }^{(19)}$. All first-incident primary prostate cancers were considered as cases in this study.

\section{Statistical analyses}

From the 5141 male participants in the SU.VI.MAX study, we excluded forty-one men who reported a cancer diagnosis before the start of the follow-up. Among the remaining participants, 3313 provided at least three valid 24-h dietary records within the first 2 years of follow-up, and thus remained available for analysis. Only the 24-h dietary records collected at the beginning of the study (first 2 years) were taken into account in the analyses and considered as baseline data. Mean dietary intakes were calculated across these repeated 24-h records. As the proportion of missing values for each covariate was low $(<5 \%)$, they were replaced by the sex-specific mode value. This classical method is used very often in large-scale epidemiological studies in order to limit the loss of subjects with at least one missing value in multivariate models ${ }^{(20,21)}$.

Hazard ratios (HR) and $95 \%$ CI obtained from Cox proportional hazards models, with age as the primary time variable, were used to characterise the association between tertiles of fruit and vegetable intakes and incidence of prostate cancer. Dietary intakes of interest were as follows: total fruits and non-starchy vegetables, fruits (including 100\% fruit juices), non-starchy vegetables, tomato products, potatoes and legumes (beans, lentils and peas as well as soya + maize and chestnuts that were grouped with legumes due to their high complex carbohydrate content). Participants contributed person-time until the date of diagnosis of prostate cancer, the date of last completed questionnaire, the date of death or 30 September 2007, whichever occurred first. Participants who reported a cancer other than prostate cancer during the study period ( $n$ 163) were included and censored at the date of diagnosis 
(except those with basal cell skin carcinoma, which was not considered to be cancer). Participants who were lost to follow-up were included in the analysis and censored at the date of last completed questionnaire. We confirmed that the assumptions of proportionality were satisfied through examination of the log-log (survival) $v$. log-time plots for all studied food groups. Tests for linear trend were performed using the ordinal score on tertiles of dietary intake. Multivariate models were adjusted for factors constitutive to the study design (initial SU.VI.MAX trial intervention group (yes/no), number of dietary records (continuous)), socio-demographic variables (age (timescale) and educational level (primary, secondary or university)), lifestyle factors (smoking status (never, former or current), physical activity (irregular $<1 \mathrm{~h} / \mathrm{d}$ or $\geq 1 \mathrm{~h} / \mathrm{d}$ walking or equivalent) and alcohol intake (continuous)), anthropometric factors (height (continuous) and BMI (continuous)), factors indicating higher individual susceptibility to prostate cancer (family history of prostate cancer (yes/no) and baseline PSA concentrations (continuous)) and dietary factors (dietary intakes of energy without alcohol, $\mathrm{Ca}$, dairy products (continuous) and plasma $\alpha$-tocopherol and Se concentrations (continuous)).
These dietary factors were those for which the association with prostate cancer risk was established or suggested according to the 2014 WCRF report ${ }^{(9)}$.

Analyses were performed overall and separately for low-grade (Gleason $<7$ ) and high-grade (Gleason $\geq 7$ ) prostate cancer. Interactions with the SU.VI.MAX antioxidant supplementation/ placebo group were tested. All tests were two-sided, and $P<0.05$ was considered to be statistically significant. SAS version 9.3 (SAS Institute Inc.) was used for analyses.

\section{Results}

During a median follow-up of 12.6 years (37 877 person-years), 139 men developed a first, primary prostate cancer with a mean age at diagnosis of 63 years. A total of $5 \cdot 2 \%$ of the participants were lost to follow-up. The mean number of dietary records per subject was 9.7 (SD 3.3). Table 1 presents the characteristics of the participants according to tertiles of total fruit and non-starchy vegetable intakes. The mean total fruit and non-starchy vegetable intake was 444.9 (SD 197) g/d. In all, $55.5 \%$ of the study population

Table 1. Baseline characteristics of the participants ( $n$ 3313) according to tertiles of total fruit and non-starchy vegetable intakes, SUpplémentation en VItamines et Minéraux AntioXydants cohort, France, 1994-2007

(Mean values and standard deviations; numbers of participants and percentages)

\begin{tabular}{|c|c|c|c|c|c|c|}
\hline & \multicolumn{2}{|c|}{ Tertile 1 (n 1104) } & \multicolumn{2}{|c|}{ Tertile 2 (n 1105) } & \multicolumn{2}{|c|}{ Tertile 3 (n 1104) } \\
\hline & Mean & SD & Mean & SD & Mean & SD \\
\hline Age (years) & $51 \cdot 2$ & 4.5 & $52 \cdot 0$ & 4.7 & $52 \cdot 3$ & 4.8 \\
\hline $\mathrm{BMI}\left(\mathrm{kg} / \mathrm{m}^{2}\right)$ & $25 \cdot 5$ & $3 \cdot 1$ & $25 \cdot 3$ & 2.9 & $25 \cdot 2$ & $3 \cdot 2$ \\
\hline$\geq 25 \mathrm{~kg} / \mathrm{m}^{2 *}$ & 613 & $55 \cdot 5$ & 581 & $52 \cdot 6$ & 558 & $50 \cdot 5$ \\
\hline Height (cm) & $173 \cdot 2$ & $6 \cdot 2$ & $173 \cdot 5$ & $6 \cdot 5$ & $174 \cdot 2$ & $6 \cdot 2$ \\
\hline Intervention group of the initial trial (yes) ${ }^{\star}$ & 570 & $51 \cdot 6$ & 563 & $51 \cdot 0$ & 557 & $50 \cdot 5$ \\
\hline \multicolumn{7}{|l|}{ Smoking status* } \\
\hline Never & 315 & 28.5 & 382 & 34.6 & 418 & $37 \cdot 9$ \\
\hline Former & 569 & $51 \cdot 5$ & 589 & $53 \cdot 3$ & 588 & $53 \cdot 3$ \\
\hline Current & 220 & $19 \cdot 9$ & 134 & $12 \cdot 1$ & 98 & 8.9 \\
\hline \multicolumn{7}{|l|}{ Physical activity* } \\
\hline Irregular & 289 & $26 \cdot 2$ & 244 & $22 \cdot 1$ & 250 & $22 \cdot 6$ \\
\hline$<1 \mathrm{~h} / \mathrm{d}$ walking or equivalent & 250 & $22 \cdot 6$ & 278 & $25 \cdot 2$ & 254 & $23 \cdot 0$ \\
\hline$\geq 1 \mathrm{~h} / \mathrm{d}$ walking or equivalent & 565 & $51 \cdot 2$ & 583 & $52 \cdot 8$ & 600 & $54 \cdot 3$ \\
\hline \multicolumn{7}{|l|}{ Educational level ${ }^{*}$} \\
\hline Primary & 278 & $25 \cdot 2$ & 255 & $23 \cdot 1$ & 231 & $20 \cdot 9$ \\
\hline Secondary & 422 & $38 \cdot 2$ & 372 & $33 \cdot 7$ & 381 & 34.5 \\
\hline University & 404 & $36 \cdot 6$ & 478 & $43 \cdot 3$ & 492 & $44 \cdot 6$ \\
\hline Family history of prostate cancer (yes) ${ }^{\star} \dagger$ & 59 & $5 \cdot 3$ & 63 & $5 \cdot 7$ & 49 & 4.4 \\
\hline Plasma PSA level $(\mu \mathrm{g} / \mathrm{l})$ & $1 \cdot 2$ & 1.4 & $1 \cdot 3$ & 1.4 & $1 \cdot 3$ & $1 \cdot 8$ \\
\hline Energy intake (kJ/d) & $8483 \cdot 0$ & $2079 \cdot 4$ & $9453 \cdot 3$ & $1975 \cdot 7$ & $10453 \cdot 3$ & $2266 \cdot 9$ \\
\hline Energy intake $(\mathrm{kcal} / \mathrm{d})$ & $2027 \cdot 5$ & $497 \cdot 0$ & $2259 \cdot 4$ & $472 \cdot 2$ & $2498 \cdot 4$ & $541 \cdot 8$ \\
\hline Alcohol intake $(\mathrm{g} / \mathrm{d})$ & 33.4 & $27 \cdot 4$ & $29 \cdot 7$ & 23.6 & $24 \cdot 3$ & $21 \cdot 6$ \\
\hline Total fruit and non-starchy vegetable intakes $(\mathrm{g} / \mathrm{d})$ & $243 \cdot 6$ & $71 \cdot 0$ & $427 \cdot 2$ & $47 \cdot 3$ & 663.9 & $144 \cdot 3$ \\
\hline Fruit intake $(\mathrm{g} / \mathrm{d}) \ddagger$ & $102 \cdot 6$ & $60 \cdot 4$ & $220 \cdot 0$ & $71 \cdot 7$ & $390 \cdot 8$ & $144 \cdot 8$ \\
\hline Non-starchy vegetable intake (g/d) & $140 \cdot 5$ & $53 \cdot 3$ & $206 \cdot 4$ & $65 \cdot 7$ & $272 \cdot 3$ & $95 \cdot 2$ \\
\hline Tomato products intake $(\mathrm{g} / \mathrm{d})$ & $23 \cdot 8$ & $21 \cdot 7$ & $34 \cdot 4$ & $26 \cdot 8$ & $44 \cdot 8$ & $38 \cdot 3$ \\
\hline Legume intake $(\mathrm{g} / \mathrm{d}) \S$ & $20 \cdot 2$ & $24 \cdot 3$ & 23.3 & $24 \cdot 3$ & $24 \cdot 7$ & $24 \cdot 8$ \\
\hline Potato intake $(\mathrm{g} / \mathrm{d})$ & 85.9 & $62 \cdot 6$ & 89 & $61 \cdot 2$ & $93 \cdot 6$ & $69 \cdot 0$ \\
\hline Dairy product intake $(\mathrm{g} / \mathrm{d})$ & $266 \cdot 5$ & $155 \cdot 1$ & $298 \cdot 8$ & $163 \cdot 5$ & 328.4 & $174 \cdot 2$ \\
\hline Ca intake $(\mathrm{mg} / \mathrm{d})$ & $889 \cdot 8$ & 312.5 & $1008 \cdot 3$ & 308.9 & $1143 \cdot 7$ & $340 \cdot 6$ \\
\hline Plasma $a$-tocopherol level $(\mu \mathrm{mol} / \mathrm{l})$ & 31.9 & $7 \cdot 8$ & $32 \cdot 3$ & $7 \cdot 5$ & 31.9 & $7 \cdot 4$ \\
\hline Plasma Se level $(\mu \mathrm{mol} / \mathrm{l})$ & $1 \cdot 1$ & 0.2 & $1 \cdot 1$ & 0.2 & $1 \cdot 1$ & 0.2 \\
\hline
\end{tabular}

PSA, prostate-specific antigen.

${ }^{*} n$ and \%.

$\dagger$ Among first-degree relatives.

$\ddagger$ Including $100 \%$ fruit juices.

$\S$ Legumes (beans, lentils, peas, soya) + maize and chestnuts. 
Table 2. Associations between tertiles of fruit, non-starchy vegetable, tomato products, potatoes and legume intakes and prostate cancer risk from multivariate Cox proportional hazards models, SUpplémentation en VItamines et Minéraux AntioXydants (SU.VI.MAX) cohort, France, 1994-2007 (139 cases out of 3313 men) $)^{\star}$ (Hazard ratios (HR) and $95 \%$ confidence intervals)

\begin{tabular}{|c|c|c|c|c|c|c|}
\hline & \multirow{2}{*}{$\begin{array}{c}\text { Tertile } 1 \\
\text { HR }\end{array}$} & \multicolumn{2}{|c|}{ Tertile 2} & \multicolumn{2}{|c|}{ Tertile 3} & \multirow[b]{2}{*}{$P_{\text {trend }}$} \\
\hline & & $\mathrm{HR}$ & $95 \% \mathrm{Cl}$ & $\mathrm{HR}$ & $95 \% \mathrm{Cl}$ & \\
\hline \multicolumn{7}{|c|}{ Total fruits and non-starchy vegetables } \\
\hline Number of cases/person-years & $48 / 12475$ & \multicolumn{2}{|c|}{$40 / 12741$} & \multicolumn{2}{|c|}{$51 / 12663$} & \\
\hline Multivariate & 1 & 0.71 & $0.46,1.09$ & 0.73 & $0.46,1.16$ & 0.25 \\
\hline \multicolumn{7}{|l|}{ Fruits } \\
\hline Number of cases/person-years & $51 / 12431$ & \multicolumn{2}{|c|}{$38 / 12652$} & \multicolumn{2}{|c|}{$50 / 12784$} & \\
\hline Multivariate & 1 & 0.55 & $0.35,0.89$ & 0.76 & $0.49,1.18$ & 0.25 \\
\hline \multicolumn{7}{|l|}{ Non-starchy vegetables } \\
\hline Number of cases/person-years & $41 / 12530$ & \multicolumn{2}{|c|}{$46 / 12730$} & \multicolumn{2}{|c|}{$52 / 12608$} & \\
\hline Multivariate & 1 & 1.03 & $0.67,1.58$ & 0.98 & $0.62,1.53$ & 0.91 \\
\hline \multicolumn{7}{|l|}{ Tomato products } \\
\hline Number of cases/person-years & $40 / 12541$ & \multicolumn{2}{|c|}{$42 / 12708$} & \multicolumn{2}{|c|}{$57 / 12630$} & \\
\hline Multivariate & 1 & $1 \cdot 12$ & $0.72,1.74$ & 1.44 & $0.94,2 \cdot 21$ & 0.09 \\
\hline \multicolumn{7}{|l|}{ Potatoes } \\
\hline Number of cases/person-years & $47 / 12431$ & \multicolumn{2}{|c|}{$45 / 12785$} & \multicolumn{2}{|c|}{$47 / 12652$} & \\
\hline Multivariate & 1 & 0.85 & $0.55,1.30$ & 0.93 & $0.56,1.45$ & 0.77 \\
\hline \multicolumn{7}{|l|}{ Legumes } \\
\hline Number of cases/person-years & $49 / 12409$ & \multicolumn{2}{|c|}{$54 / 12730$} & \multicolumn{2}{|c|}{$36 / 12740$} & \\
\hline Multivariate & 1 & 0.99 & $0.66,1.48$ & 0.53 & $0.34,0.85$ & 0.009 \\
\hline
\end{tabular}

* Cut-off points for tertiles of intake were 345.3 and $511.7 \mathrm{~g} / \mathrm{d}$ for total fruits and non-starchy vegetables; 284.4 and $401.5 \mathrm{~g} / \mathrm{d}$ for fruits; 336.7 and $447.9 \mathrm{~g} / \mathrm{d}$ for vegetables; 172.5 and $193.8 \mathrm{~g} / \mathrm{d}$ for tomato products; 506.3 and $544.2 \mathrm{~g} / \mathrm{d}$ for potatoes; 6.2 and $26.5 \mathrm{~g} / \mathrm{d}$ for legumes. Multivariate models were adjusted for age (timescale), energy intake without alcohol, intervention group of the initial SU.VI.MAX trial, number of 24-h dietary records, smoking status, educational level, physical activity, height, BMI, alcohol intake, family history of prostate cancer, baseline plasma prostate-specific antigen concentration, $\mathrm{Ca}$ intake, dairy product intake and plasma $a$-tocopherol and Se concentrations.

reached the $400 \mathrm{~g} / \mathrm{d}$ minimal French recommendation ${ }^{(22)}$. The mean legume intake was $22 \cdot 0$ (sD 24.3) g/d.

Table 2 summarises the associations between fruit, vegetable, tomato products, potato and legume intakes and prostate cancer risk. An inverse association was observed between prostate cancer risk and tertiles of legume intake $\left(\mathrm{HR}_{\mathrm{T} 3 v \cdot \mathrm{T} 1}=0.53 ; 95 \% \mathrm{CI}\right.$ $\left.0.34,0.85 ; P_{\text {trend }}=0.009\right)$. The survival plot corresponding to legume intake is provided Fig. 1. No association was observed between prostate cancer risk and tertiles of intakes of fruits $\left(P_{\text {trend }}=0 \cdot 25\right)$, vegetables $\left(P_{\text {trend }}=0.91\right)$, potatoes $\left(P_{\text {trend }}=0.77\right)$ and tomato products $\left(P_{\text {trend }}=0 \cdot 09\right)$ (Table 2$)$. No interaction was detected with the SU.VI.MAX intervention group $(P>0 \cdot 29)$ for all dietary exposures.

Table 3 summarises the associations between legume intake and prostate cancer risk separately for low- and high-grade cancers. An inverse association was observed between lowgrade prostate cancer risk and tertiles of legume intake $\left(P_{\text {trend }}=0.03\right)$, whereas no association was observed for high-grade prostate cancer $\left(P_{\text {trend }}=0 \cdot 35\right)$. No difference was observed between low- and high-grade prostate cancer for other studied food groups (data not shown).

In sensitivity analyses, results remained unchanged when cancer cases diagnosed during the first 2 years of follow-up were excluded (five cases in 3313 men, $\mathrm{HR}_{\mathrm{T} 3 v . \mathrm{T} 1}=0 \cdot 60 ; 95 \% \mathrm{CI}$ $0.37,0.95 ; \quad P_{\text {trend }}=0.03$ for legumes) or when considering only men who completed at least six 24-h dietary records during the first 2 years of follow-up ( 123 cases in 2771 men). Likewise, there was no modification in the results when soya and soya products were excluded from the legume group $\left(\mathrm{HR}_{\mathrm{T} 3 v . \mathrm{T} 1}=0.56 ; 95 \% \mathrm{CI} 0.35,0.89 ; P_{\text {trend }}=0.02\right)$. Results were unchanged when chestnuts and maize were not included with

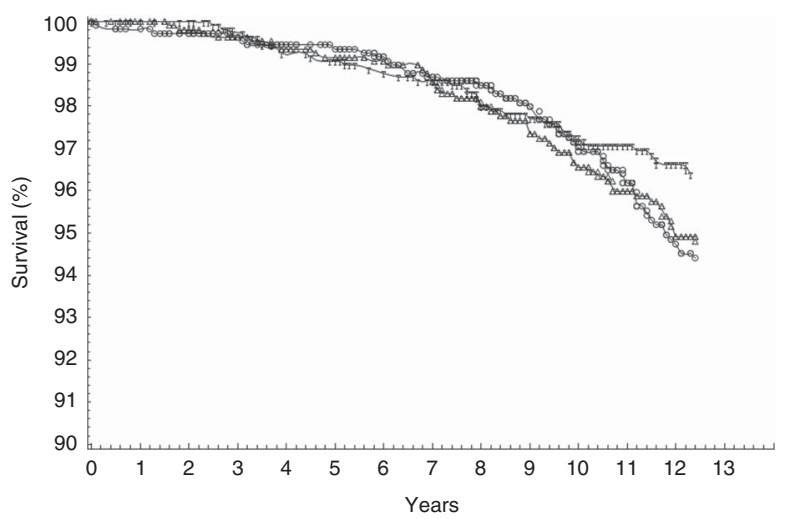

Fig. 1. Survival plots for associations between tertiles of legume intake and prostate cancer risk by multivariable Cox model, SUpplémentation en VItamines et Minéraux AntioXydants (SU.VI.MAX) cohort, France, 1994-2007; 139 cases out of 3313 men. Models were adjusted for age (timescale), energy intake without alcohol, intervention group of the initial SU.VI.MAX trial, number of 24-h dietary records, smoking status, educational level, physical activity, height, BMI, alcohol intake, family history of prostate cancer, baseline plasma prostatespecific antigen (PSA) concentration, calcium intake, dairy product intake and plasma $a$-tocopherol and selenium concentrations. $\triangle \Delta \Delta$, Tertile 1; ९৩৩, tertile 2; II士, tertile 3 .

legumes $\left(\mathrm{HR}_{\mathrm{T} 3 v \cdot \mathrm{T} 1}=0.52 ; 95 \% \mathrm{CI} 0.32,0 \cdot 86 ; P_{\text {trend }}=0.02\right)$. The proportion of subjects with at least one missing value was similar between cases and controls (20 and 19\%, respectively, $P=0 \cdot 8)$. When analyses were carried out after excluding subjects with at least one missing value for covariates ( $n$ 635), the results were similar, although borderline significant owing to loss of statistical power (for legumes: $\mathrm{HR}_{\mathrm{T} 3 v \cdot \mathrm{T} 1}=0 \cdot 65 ; 95 \% \mathrm{CI}$ $0.39,1.08 ; P_{\text {trend }}=0 \cdot 10$ ). 
Table 3. Associations between tertiles of legume intake and low-grade/high-grade prostate cancer risk from multivariate Cox proportional hazards models, Supplémentation en Vitamines et Minéraux Antioxydants (SU.VI.MAX) cohort, France, 1994-2007*

(Hazard ratios (HR) and $95 \%$ confidence intervals)

\begin{tabular}{|c|c|c|c|c|c|c|}
\hline & \multirow{2}{*}{$\begin{array}{c}\text { Tertile } 1 \\
\text { HR }\end{array}$} & \multicolumn{2}{|c|}{ Tertile 2} & \multicolumn{2}{|c|}{ Tertile 3} & \multirow[b]{2}{*}{$P_{\text {trenc }}$} \\
\hline & & $\mathrm{HR}$ & $95 \% \mathrm{Cl}$ & $\mathrm{HR}$ & $95 \% \mathrm{Cl}$ & \\
\hline \multicolumn{7}{|c|}{ Low-grade prostate cancer (Gleason $<7$ ) } \\
\hline Number of cases/person-years & 25/12215 & \multicolumn{2}{|c|}{$27 / 12473$} & \multicolumn{2}{|c|}{$16 / 12585$} & \\
\hline Multivariate & 1 & 0.99 & $0.56,1.75$ & 0.46 & $0.23,0.91$ & 0.03 \\
\hline \multicolumn{7}{|c|}{ High-grade prostate cancer (Gleason $\geq 7$ ) } \\
\hline Number of cases/person-years & $21 / 12180$ & \multicolumn{2}{|c|}{$24 / 12481$} & \multicolumn{2}{|c|}{$19 / 12631$} & \\
\hline Multivariate & 1 & 1.07 & $0.59,1.97$ & 0.73 & $0.38,1.43$ & 0.35 \\
\hline
\end{tabular}

\section{Discussion}

In this prospective study, legume intake was associated with reduced prostate cancer risk, whereas no association was observed for fruit, non-starchy vegetable, tomato products and potatoes intakes.

Our null results are consistent with results of the 2014 WCRF/ $\mathrm{AICR}^{(9)}$ meta-analyses of prospective studies, in which no association was observed between prostate cancer risk and vegetable intake (summary HR for a $100 \mathrm{~g} / \mathrm{d}$ increment $=0.99$; $95 \%$ CI 0.98, 1.00; thirteen prospective studies included), tomato product intake (summary HR for a $100 \mathrm{~g} / \mathrm{d}$ increment $=0.93$; 95\% CI 0.79, 1.09; seven studies) and fruit intake (summary HR for a $100 \mathrm{~g} / \mathrm{d}$ increment $=1.00 ; 95 \%$ CI $0.99,1.01$; sixteen studies).

In contrast, only three prospective studies have been published on legume intake and prostate cancer risk ${ }^{(10-12)}$, among which two observed inverse associations ${ }^{(10,11)}$ in line with our results. In the Multiethnic Cohort Study, Park et al. ${ }^{(10)}$ reported a significant inverse trend for total prostate cancer risk $\left(\mathrm{HR}=0.90 ; 95 \% \mathrm{CI} 0.81,1.01 ; P_{\text {trend }}=0.01\right)$. In our study, the association between legume intake and prostate cancer risk tended to be stronger in low-grade prostate cancer; however, the number of cases was low in the analyses stratified by the Gleason grade, and thus should be considered with caution. Park et al. ${ }^{(10)}$ reported a significant inverse association for non-localised prostate cancer (defined as cancer that was regional or distant) grouped with high-grade prostate cancer (defined as Gleason score $\geq 7$ ), but results for low-grade prostate cancer were not presented. In the Netherlands Cohort Study, Schuurman et al. ${ }^{(11)}$ reported an inverse association between legume intake and prostate cancer risk $(\mathrm{HR}=0.71 ; 95 \%$ CI $0.51,0.98 ; P=0.01)$. In contrast, Smit et al. ${ }^{(12)}$ reported no association with intake of legumes in a study in Porto Rico; however, the outcome was cancer mortality and not cancer incidence.

Furthermore, two prospective studies observed no association with prostate cancer risk or mortality but they focused only on boiled beans ${ }^{(23)}$ and dried beans ${ }^{(24)}$. Two other prospective studies investigated the association between beans, lentils and peas and prostate cancer risk: one showed an inverse association ${ }^{(25)}$, whereas the other study reported no association ${ }^{(26)}$.
The inverse association between legume intake and prostate cancer risk is supported by mechanistic data from experimental studies. Several bioactive compounds are contained in legumes, and among them antioxidants. However, they do not seem to play an important role in prostate cancer prevention as fruits and vegetables are also abundant sources of antioxidants, but were not associated with prostate cancer risk (in this study as in most of the existing literature $)^{(9)}$. Besides, antioxidant supplementation in the SU.VI.MAX trial was not associated with prostate cancer risk ${ }^{(27)}$.

Dietary fibre is another major component of legumes and probably plays a key role in the observed association. Indeed, in the SU.VI.MAX cohort, we previously observed ${ }^{(13)}$ an inverse association between prostate cancer risk and total dietary fibre intake, and more specifically with dietary fibre intake from legumes and insoluble dietary fibre intake (legume fibre being mainly insoluble $)^{(28,29)}$. Besides, dietary fibre content is higher in legumes than in fruits and non-starchy vegetables, which may contribute to explain the null result observed for the latter food groups. First, experimental studies showed that dietary fibre exerts a down-regulation role on inflammation ${ }^{(30)}$, probably through the production of SCFA when fibres are fermented in the colon by gut microbiota. Fermentation products, particularly butyrate $^{(31)}$ and propionate ${ }^{(32)}$, have shown anti-inflammatory properties. Experimental data suggest that inflammation has a pro-carcinogenic role in prostate cancer development ${ }^{(26,33-35)}$. Consistently, in a prospective case-control study nested in the SU.VI.MAX cohort, we observed that the baseline plasma concentration of highly sensitive C-reactive protein (hs-CRP) was directly associated with increased prostate cancer risk ${ }^{(36)}$. In the subsample of the present study with available data ( $n$ 832), the level of hs-CRP was lower in subjects of the third $v$. first tertile of legume intake (1.9 (SD 3.0) v. 3.0 (SD 6.7) mg/l; $P=0.03$, data not tabulated). Second, increased concentrations of circulating sex hormones could be associated with a greater risk of prostate cancer ${ }^{(5)}$. Dietary fibre may reduce concentrations of circulating oestrogens and androgens, notably through increased sex hormone-binding globulin concentration ${ }^{(37)}$, modified enterohepatic circulation of steroid hormones ${ }^{(38,39)}$ and increased faecal excretion of these hormones, resulting from binding to insoluble fibres ${ }^{(40)}$. Finally, experimental studies suggested that insulin resistance and hyperinsulinaemia, by 
increasing insulin-like growth factor (IGF) concentrations, may stimulate prostate carcinogenesis ${ }^{(4)}$. Several studies have suggested that dietary fibre may reduce insulin resistance ${ }^{(41,42)}$, notably through a decrease in carbohydrate absorption rate ${ }^{(28,43,44)}$, and an increase in IGF binding protein 3 concentrations ${ }^{(45)}$, leading to decreased IGF bioactivity ${ }^{(4,33)}$.

In the legume food group, a role of soya phyto-oestrogens has also been postulated to explain the inverse association with prostate cancer risk $^{(9)}$. However, in our study and in another prospective study ${ }^{(10)}$, significant inverse associations between legume intake and prostate cancer risk were observed even after exclusion of soya and soya products, suggesting that phyto-oestrogens might not entirely explain the observed association. Other legumes also contain phyto-oestrogens but the concentrations are very small compared with the ones observed in soya-based foods (e.g. $<70 v$. $>6400 \mu \mathrm{g} / 100 \mathrm{~g}$ in soya) ${ }^{(46)}$.

Strengths of this study include its prospective design, long follow-up and detailed evaluation of dietary intake by repeated 24-h records. However, some limitations should be acknowledged. First, the relatively small number of cases may have limited our ability to detect some of the hypothesised associations. However, this is unlikely to explain the observed relationships that were statistically significant despite this potential power limitation. Next, participants became aware of their baseline PSA values (if $>4.0 \mu \mathrm{g} / \mathrm{l}$ ) only at the end of the trial phase (after 2003). Therefore, it could not have influenced their baseline dietary and other lifestyle behaviours, and thus this is unlikely to explain the significant observed associations. However, PSA testing in our cohort must be taken into account when extrapolating our results to the whole middle-aged male French population, as it may have influenced the number of cases diagnosed at the end of follow-up and probably led to an over-representation of early-stage prostate cancers. Finally, the observed relationships could be partly affected by unmeasured or residual confounding. However, main potential confounding factors for prostate cancer risk have been accounted for in this study, notably lifestyle factors indicating 'healthy behaviours', anthropometric factors and established or suspected dietary factors according to the $2014 \mathrm{WCRF} / \mathrm{AICR}$ report ${ }^{(9)}$. Thus, it is unlikely that residual confounding entirely explains the observed associations.

In conclusion, this prospective study brings new insights into the role of fruit, vegetable and legume intakes in prostate carcinogenesis. It confirms the null association between fruit and non-starchy vegetable intakes and prostate cancer risk observed in most previous studies ${ }^{(9)}$. In contrast, our results suggest an inverse association between legume intake and prostate cancer risk, supported by mechanistic plausibility. As very few prospective studies have been published on the topic, these results should be confirmed by large-scale observational and intervention studies.

\section{Acknowledgements}

The authors thank Nathalie Arnault, Younes Esseddik, Paul Flanzy, Mohand Ait Oufella, Yasmina Chelghoum and Van Than Duong (computer scientists) as well as Anne-Sophie Chhim, Véronique Gourlet, Fabien Szabo, Laurent Bourhis and Stephen Besseau (statisticians) for their technical contribution to the SU.VI.MAX study.

M. D. was funded by a $\mathrm{PhD}$ grant from the 'Cancéropôle Ile-de-France' (public funding from the Paris region). The funders had no role in the design, implementation, analysis or interpretation of the data.

The authors' responsibilities were as follows - A. D. and M. T. designed the research; S. H., M. T. and P. G. conducted the research; A. D. performed statistical analysis and wrote the paper; M. T. supervised the study; M. D., P. L.-M., P. G., S. H. and L. Z. contributed to the data interpretation and revised each draft for important intellectual content; and M. T. had primary responsibility for the final content. All the authors read and approved the final version of the manuscript.

There are no conflicts of interest to declare.

\section{References}

1. Institut National du Cancer (2015) Cancers in France in 2014. The Main Part of the Facts and Figures. Boulogne Billancourt: Institut National du Cancer.

2. Ferlay J, Soerjomataram I, Dikshit R, et al. (2015) Cancer incidence and mortality worldwide: sources, methods and major patterns in GLOBOCAN 2012. Int J Cancer 136, E359-E386.

3. Lin PH, Aronson W \& Freedland SJ (2015) Nutrition, dietary interventions and prostate cancer: the latest evidence. $B M C$ Med 13, 3 .

4. Barnard RJ, Aronson WJ, Tymchuk CN, et al. (2002) Prostate cancer: another aspect of the insulin-resistance syndrome? Obes Rev 3, 303-308.

5. Bosland MC (2000) The role of steroid hormones in prostate carcinogenesis. J Natl Cancer Inst Monogr 27, 39-66.

6. Giovannucci E (2003) Nutrition, insulin, insulin-like growth factors and cancer. Horm Metab Res 35, 694-704.

7. Nimptsch K, Kenfield S, Jensen MK, et al. (2011) Dietary glycemic index, glycemic load, insulin index, fiber and wholegrain intake in relation to risk of prostate cancer. Cancer Causes Control 22, 51-61.

8. Willis MS \& Wians FH (2003) The role of nutrition in preventing prostate cancer: a review of the proposed mechanism of action of various dietary substances. Clin Chim Acta 330, 57-83.

9. World Cancer Research Fund/The American Institute for Cancer Research (2014) Diet, nutrition, physical activity and prostate cancer. Continuous update project.

10. Park SY, Murphy SP, Wilkens LR, et al. (2008) Legume and isoflavone intake and prostate cancer risk: the Multiethnic Cohort Study. Int J Cancer 123, 927-932.

11. Schuurman AG, Goldbohm RA, Dorant E, et al. (1998) Vegetable and fruit consumption and prostate cancer risk: a cohort study in the Netherlands. Cancer Epidemiol Biomarkers Prev 7, 673-680.

12. Smit E, Garcia-Palmieri MR, Figueroa NR, et al. (2007) Protein and legume intake and prostate cancer mortality in Puerto Rican men. Nutr Cancer 58, 146-152.

13. Deschasaux M, Pouchieu C, His M, et al. (2014) Dietary total and insoluble fiber intakes are inversely associated with prostate cancer risk. J Nutr 144, 504-510.

14. Hercberg S, Galan P, Preziosi P, et al. (2004) The SU.VI.MAX Study: a randomized, placebo-controlled trial of the health effects of antioxidant vitamins and minerals. Arch Intern Med 164, 2335-2342.

15. Le Moullec N, Deheeger M, Preziosi P, et al. (1996) Validation du manuel photo utilisé pour l'enquête alimentaire de l'étude 
SU.VI.MAX (Validation of the food portion size booklet used in the SU.VI.MAX study). Cah Nutr Diet 31, 158-164.

16. Hercberg S (2005) Table of Composition SU.VI.MAX of Food. Paris: INSERM/Economica editions.

17. Hercberg S, Preziosi P, Briancon S, et al. (1998) A primary prevention trial using nutritional doses of antioxidant vitamins and minerals in cardiovascular diseases and cancers in a general population: the SU.VI.MAX study design, methods, and participant characteristics. SUpplementation en VItamines et Mineraux AntioXydants. Control Clin Trials 19 , 336-351.

18. Vuilleumier JP, Keller HE, Gysel D, et al. (1983) Clinical chemical methods for the routine assessment of the vitamin status in human populations. Part I: the fat-soluble vitamins A and E, and beta-carotene. Int J Vitam Nutr Res 53, 265-272.

19. World Health Organization (2010) ICD-10, International Classification of Diseases and Related Health Problems, 10th revision. Geneva: WHO.

20. Gmel G (2001) Imputation of missing values in the case of a multiple item instrument measuring alcohol consumption. Stat Med 20, 2369-2381.

21. Ludbrook J (2008) Outlying observations and missing values: how should they be handled? Clin Exp Pharmacol Physiol 35 670-678.

22. Hercberg S, Chat-Yung S \& Chaulia M (2008) The French National Nutrition and Health Program: 2001-2006-2010. Int J Public Health 53, 68-77.

23. Iso H \& Kubota Y (2007) Nutrition and disease in the Japan Collaborative Cohort Study for Evaluation of Cancer (JACC). Asian Pac J Cancer Prev 8, Suppl., 35-80.

24. Kirsh VA, Peters U, Mayne ST, et al. (2007) Prospective study of fruit and vegetable intake and risk of prostate cancer. J Natl Cancer Inst 99, 1200-1209.

25. Mills PK, Beeson WL, Phillips RL, et al. (1989) Cohort study of diet, lifestyle, and prostate cancer in Adventist men. Cancer 64, 598-604.

26. Hsing AW, Sakoda LC \& Chua S Jr (2007) Obesity, metabolic syndrome, and prostate cancer. Am J Clin Nutr 86, s843-s857.

27. Meyer F, Galan P, Douville P, et al. (2005) Antioxidant vitamin and mineral supplementation and prostate cancer prevention in the SU.VI.MAX trial. Int J Cancer 116, 182-186.

28. Guillon F \& Champ MM (2002) Carbohydrate fractions of legumes: uses in human nutrition and potential for health. $\mathrm{BrJ}$ Nutr 88, Suppl. 3, S293-S306.

29. Liljeberg EH (2002) Resistant starch content in a selection of starchy foods on the Swedish market. Eur J Clin Nutr 56, 500-505.

30. King DE, Egan BM, Woolson RF, et al. (2007) Effect of a high-fiber diet vs a fiber-supplemented diet on C-reactive protein level. Arch Intern Med 167, 502-506.

31. Vinolo MA, Rodrigues HG, Nachbar RT, et al. (2011) Regulation of inflammation by short chain fatty acids. Nutrients 3, 858-876.
32. Al-Lahham S, Roelofsen H, Rezaee F, et al. (2012) Propionic acid affects immune status and metabolism in adipose tissue from overweight subjects. Eur J Clin Invest $\mathbf{4 2}$, 357-364.

33. Arcidiacono B, Iiritano S, Nocera A, et al. (2012) Insulin resistance and cancer risk: an overview of the pathogenetic mechanisms. Exp Diabetes Res 2012, 789174.

34. Rojas A, Liu G, Coleman I, et al. (2011) IL-6 promotes prostate tumorigenesis and progression through autocrine crossactivation of IGF-IR. Oncogene 30, 2345-2355.

35. Sfanos KS \& De Marzo AM (2012) Prostate cancer and inflammation: the evidence. Histopathology 60, 199-215.

36. Touvier M, Fezeu L, Ahluwalia N, et al. (2013) Association between prediagnostic biomarkers of inflammation and endothelial function and cancer risk: a nested case-control study. Am J Epidemiol 177, 3-13.

37. Longcope C, Feldman HA, McKinlay JB, et al. (2000) Diet and sex hormone-binding globulin. J Clin Endocrinol Metab 85, 293-296.

38. Cohen LA, Zhao Z, Zang EA, et al. (1996) Wheat bran and psyllium diets: effects on $\mathrm{N}$-methylnitrosourea-induced mammary tumorigenesis in F344 rats. J Natl Cancer Inst 88, 899-907.

39. Gerber M (1996) Fiber and breast cancer: another piece of the puzzle-but still an incomplete picture. J Natl Cancer Inst 88, 857-858.

40. Ross JK, Pusateri DJ \& Shultz TD (1990) Dietary and hormonal evaluation of men at different risks for prostate cancer: fiber intake, excretion, and composition, with in vitro evidence for an association between steroid hormones and specific fiber components. Am J Clin Nutr 51, 365-370.

41. Johnston KL, Thomas EL, Bell JD, et al. (2010) Resistant starch improves insulin sensitivity in metabolic syndrome. Diabet Med 27, 391-397.

42. Robertson MD, Bickerton AS, Dennis AL, et al. (2005) Insulinsensitizing effects of dietary resistant starch and effects on skeletal muscle and adipose tissue metabolism. Am J Clin Nutr 82, 559-567.

43. Higgins JA (2012) Whole grains, legumes, and the subsequent meal effect: implications for blood glucose control and the role of fermentation. J Nutr Metab 2012, 829238.

44. Moore MA, Park CB \& Tsuda H (1998) Soluble and insoluble fiber influences on cancer development. Crit Rev Oncol Hematol 27, 229-242.

45. Probst-Hensch NM, Wang H, Goh VH, et al. (2003) Determinants of circulating insulin-like growth factor I and insulin-like growth factor binding protein 3 concentrations in a cohort of Singapore men and women. Cancer Epidemiol Biomarkers Prev 12, 739-746.

46. French Food Safety Agency \& French Safety Agency for Health Products (2005) Safety and benefits of dietary phytoestrogens recommendations March 2005. Paris: French Food Safety Agency \& French Safety Agency for Health. 